\title{
BSPD conference to focus on creative collaboration
}

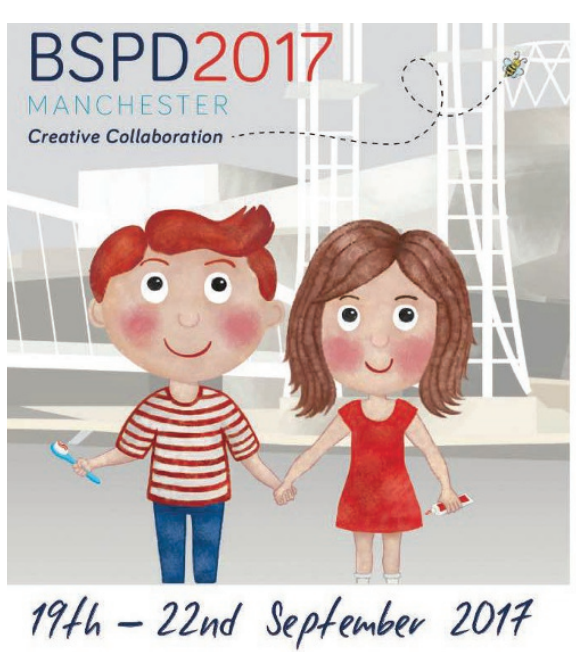

Patient care and the advancement of knowledge are exponentially enhanced when clinicians, healthcare professionals and researchers share information and work together. A key aim of the British Society of Paediatric Dentistry's (BSPD's) annual conference is to showcase such collaborations as well as to celebrate the creativity which happens to be synonymous with the host City of Manchester.

The conference will take place on 19-22 September 2017 at the Lowry Arts and Events Centre in Salford Quays. The organising committee has lined up a programme of speakers who will describe scientific developments resulting from trials or inter-hospital collaborations they are involved in. A key theme is children with complex needs for whom collaborative working across medicine and dentistry is essential.
Professor Kevin O'Brien, Director of the Healing Foundation, will launch the conference with a scene-setting talk called 'Working together to keep it simple complex problems in complex children'. The two presentations which follow have caries as a theme - the first from the perspective of the Northern Alliance collaboration given jointly by Dr Sondos Albadri and Yang See Chau, and the next from Professor Marie Therese Hosey who will discuss creative approaches to reducing the burden of the disease.

Thursday morning will start with three sessions from eminent clinicians working at the Royal Manchester Children's Hospital: Professor Zulf Mughal, Lead of the Paediatric Metabolic Bone Service, Dr Simon Jones consultant in inherited metabolic diseases and Dr Stephen Hughes, consultant paediatric immunologist.

The final morning of the conference will showcase the work that's going on to improve children's oral health both nationally and locally and will include a session with three of the UK's four Chief Dental Officers.

Claire Stevens, the incoming President of BSPD, commented: 'What we hope is that all our delegates will experience the buzz of being in Manchester and hearing first class speakers.

'It's the first time in 20 years that the BSPD conference has come back to Manchester and, as an organising committee, we plan to showcase both a great city and some very exciting creative collaborations.'

\section{BSDHT and BADT unite to drive change}

The British Society of Dental Hygiene and Therapy (BSDHT) and the British Association of Dental Therapists (BADT) have united to apply for prescribing exemptions that would broaden dental hygienists' and dental therapists' scope of practice for the benefit of their patients.

Driven by respective immediate past presidents - Michaela O'Neill and Fiona Sandom - the societies were recently given the green light by the Department of Health to move into the next stage of the campaign.

BSDHT and BADT are asking dental hygienists and therapists whether they have had to send patients away with incomplete or no treatment because they couldn't get a prescription when they needed it; how such occasions affected their ability to deliver patient care; and what it would mean to the dental hygienists and therapists to provide certain prescription-only medicines without requiring a prescription from the dentist. The societies are collecting case examples to support their cause and hope that by working together they can drive change.

www.bsdht.org.uk
Consultation opens on European dental education

The Association for Dental Education in Europe (ADEE) is inviting review and comment on its May 2017 draft Taskforce documents, that include:

- Undergraduate Dental Education: The European perspective

- Domain I - Professionalism

- Domain II - Safe and Effective Clinical Practice

- Domain III - Patient-centred Care

- Domain IV - Dentistry in Society

- Contemporaneous methods of teaching, learning and assessment, in Dental Undergraduate Education.

ADEE has represented dental schools throughout Europe since 1975 and has become an international voice of dental education. In 1999, it commissioned three taskforces to harmonise dental education systems in Europe. The popularity and influence of the resulting documents is demonstrated by the number of downloads and citations that have taken place; they have been used by many schools, educational establishments and professional organisations globally. Many institutions are now showing a preference for a learning outcomes' approach to undergraduate dental education and a focus on the dental team approach to delivery of oral healthcare.

The current suite of publications aims to 'inject a fresh new approach that reflects best academic practice for European dental education'.

The consultation runs until 16 July 2017; all documents and a feedback form can be accessed at: https://www.adee.org/ taskforces/2017consultation.html.

\section{Erratum}

Obituary Br Dent J 2017; 222: 576

The original obituary incorrectly stated 'Professor Scully was a graduate of the Royal London Dental School.' Professor Scully actually graduated from Royal Dental Hospital of London. We apologise for this error and the inconvenience caused. 